\title{
Risk of burnout among emergency physicians at a tertiary care centre in Saudi Arabia
}

\author{
Abdulmohsen Alsaawi ${ }^{1,2}$, Khaled Alrajhi ${ }^{2}$, Saad Albaiz ${ }^{2}$, Mohammed Alsultan $^{1,2}$, Majid \\ Alsalamah ${ }^{2,3}$, Shoeb Qureshi ${ }^{3}$, Abdullah Alanazi ${ }^{2,3}$ \\ 1. College of Medicine, King Saud Bin Abdulaziz University for Health Sciences, Riyadh, Saudi Arabia. 2. Emergency \\ Department, King Abdulaziz Medical City, Riyadh, Saudi Arabia. 3. College of Applied Medical Sciences, King Saud Bin \\ Abdulaziz University for Health Sciences, Riyadh, Saudi Arabia.
}

Correspondence: Abdullah Alanazi. Address: King Saud bin Abdulaziz University for Health Sciences MC-3129, PO Box 3660 Riyadh 11481, Kingdom of Saudi Arabia. E-mail: abdanazi@yahoo.com

Received: October 25, 2013

Accepted: January 6, 2014

Online Published: February 8, 2014

DOI : $10.5430 /$ jha.v3n4p20

URL: http://dx.doi.org/10.5430/jha.v3n4p20

\section{Abstract}

Background: Emergency Medicine physicians are shown to be at increased risk of burnout. In this study, we aimed to assess the risk of burnout among emergency physicians working at one of the largest Emergency Departments in Saudi Arabia.

Methods: This is an observational, cross-sectional study based on a structured questionnaire Maslach Burnout InventoryHuman Services Survey (MBI-HSS), which has been previously tested and validated extensively. The study targeted all physicians in the Emergency Department (ED) at a tertiary medical center in Riyadh. A total of 72 emergency physicians were included in the study.

Results: Overall, 53 (74\%) out of 72 subjects filled the questionnaire. Out of the 53 respondents, 45 (85\%) were males and eight (15\%) females. The years of practice experience ranged from six months to 24 years, with a median of seven years.

Burnout Inventory-Human Services Survey subscale results:

Emotional Exhaustion (EE): The mean EE score was 2.72 (SD 1.28), with 21 participants (40\%) in the high-risk zone. Depersonalization (DP): The mean DP score was 1.86 (SD 1.31), with 21 participants (40\%) in the high-risk zone. Personal Accomplishment (PA): The mean PA score was 4.5 (SD 0.9), with 17 participants (32\%) in the high-risk zone.

Conclusion: Our results are consistent with previous literature in showing that emergency physicians are at a moderate to high risk of burnout. Decision makers should take serious steps to address the threat, in order to minimize the risk of burnout and its impact on physicians as well as the patient they care for.

\section{Key words}

Burnout, Emergency medicine, Stress, Work environment

\section{I ntroduction}

Physician's physical and psychological wellbeing has gained special attention in the last decade. Work related stress and subsequent burnout could have a negative impact on work performance, as well as increased health care provider turnover 
rates, especially in the emergency medicine environment ${ }^{[1,2]}$. The Joint Commission on Accreditation of Healthcare Organizations has mandated all hospitals and health care systems to have a process for addressing physicians' physical as well as psychological health ${ }^{[3]}$.

Burnout is defined as "a syndrome of emotional exhaustion, depersonalization (impersonal response towards patients) and reduced personal accomplishment among individuals who work with people" ${ }^{[4]}$. Emergency medicine physicians have been previously found to have a greater risk of burnout compared to other medical disciplines ${ }^{[5]}$. We excluded emergency residents, newly hired, as well as the study investigators. Soft copies of Maslach Burnout Inventory-Human Services Survey (MBI-HSS) were sent as e-mails to all participants, non-responders were re-contacted by phone. As the stress syndrome progresses, providers attempt to decrease their contact with patients and staff, become less respectful listeners, and perform more tests and referrals. They may behave rudely and be quick to anger, argue, and blame. Burnout within a department or organization usually is experienced as increased turnover, absenteeism, poor morale, and patient dissatisfaction ${ }^{[6,7]}$. Several factors make Emergency Medicine a fertile environment for burnout. Overcrowding, death, critical decisions made with incomplete information, and shift work are among these factors ${ }^{[6,8]}$. Occupational burnout in physicians affects their health, personal lives and the quality of care they provide to their patients ${ }^{[9]}$. Although there are multiple burnout studies on emergency physicians from different parts of the world, we were unable to find any published studies from this region. In this study, we aimed to assess the risk of burnout among emergency physicians working at one of the largest tertiary care centers in Saudi Arabia.

\section{Methods}

\subsection{Design}

This is an observational, cross-sectional study based on a structured questionnaire "The MBI-HSS scale", which has been previously extensively tested and validated ${ }^{[4,10,11]}$. The English version of the questionnaire was used since it is the main language in our multi-cultural institution; and all participants are expected to be fluent in English. Participants included all Emergency physicians at King Abdulaziz Medical City (KAMC), Riyadh, Saudi Arabia. KAMC is an academic level 1 trauma center with an Emergency department that receives approximately 220,000 patients/year. Emergency physicians work an average of sixteen 8-hour shifts per month. Those are roughly divided between morning, evening, and night shifts. The group is made of 25 Emergency Medicine consultants, 16 Pediatric Emergency Consultants and 31 staff physicians (physicians with no specialty board certification). The consultant group consists almost entirely of board certified emergency physicians and pediatricians with Emergency Medicine fellowship training. We excluded emergency medicine residents, newly hired physicians (less than six months), as well as the study investigators. The study was approved by the Institutional Review Board of King Abdullah International Medical Research Centre (KAIMRC), National Guard Health Affairs, and Riyadh, Saudi Arabia. Participation was voluntary and all responses were anonymous. Participants were told that the study tool aims to assess one's personal experience of work, without using the term burnout to avoid sensitization.

\subsection{Data collection and analysis}

Soft copies of MBI-HSS were sent as e-mails using an electronic survey tool (MindGarden.com) to all participants, non-responders were re-contacted by phone. The questionnaire consisted of the $22 \mathrm{MBI}$-HSS questions in addition to seven questions pertaining to demographics, stress coping techniques and perceived major contributing burnout factors by the physicians (see Table 1 and Table 2). The questions are written as statements regarding the personal feelings or attitudes of the subjects (for example, "I feel depressed at work"). The statements are answered in terms how often the respondents experience these feelings, on a 7-point scale ranging from 0 representing "never" to 6 representing "every day" ${ }^{[4]}$. Data collection process took approximately 20 days from questionnaire distribution to collection. Standard descriptive statistics were used to characterize the study participants. Means and standard deviations for different subscales were obtained using Statistical Package for Social Sciences (SPSS for Mac, Version 21; SPSS, Inc., Chicago, 
IL). The MBI-HSS manual reference cutoffs were used to stratify participants into low, moderate, or high risk of burnout. The comparative values of MBI-HSS subscales (Emotional exhaustion, Depersonalization and Personal accomplishment) score were computed by the method of Maslach et al. ${ }^{[4]}$.

Table 1. Questions incorporating questionnaire before the MBI

\begin{tabular}{|c|c|c|}
\hline Serial & Parameter & Description \\
\hline 1. & Age & 25 years, 25-34; 35-44; 45-54. \\
\hline 2. & Sex & Male; Female \\
\hline 3. & Job Title & $\begin{array}{l}\text { Assistant, Associate, Consultant } \\
\text { Staff physician }\end{array}$ \\
\hline 4. & Years of emergency medicine practice & $\begin{array}{ll}\text { Assistant } & (\text { ) } \\
\text { Associate } & (\text { ) } \\
\text { Consultant } & (\text { ) } \\
\text { Staff Physician } & (\text { ) }\end{array}$ \\
\hline
\end{tabular}

Table 2. Questions incorporating questionnaire after MBI

\begin{tabular}{lll}
\hline Serial & Parameter & Description \\
\hline & & $\begin{array}{l}\text { Work overload } \\
\text { Insufficient reward }\end{array}$ \\
1. $\quad \begin{array}{l}\text { Which of the factors has the most negative effect on your } \\
\text { relationship to your work place (chose one)? }\end{array}$ & $\begin{array}{l}\text { Unfairness in dealing with different employees } \\
\text { Breakdown of work community } \\
\text { Value conflict (institutional versus personal values) } \\
\text { Other: Writing space }\end{array}$ \\
& $\begin{array}{l}\text { What techniques you use most often to alleviate work } \\
\text { related stresses? }\end{array}$ & $\begin{array}{l}\text { Writing space } \\
\text { 2. }\end{array}$ \\
Have you considered the following during the past 12 & $\begin{array}{l}\text { Changing your specialty } \\
\text { Changing hospital } \\
\text { Changing both } \\
\text { months? }\end{array}$ & Neither \\
\hline
\end{tabular}

\section{Results}

Overall, 53 (74\%) out of 72 subjects filled the questionnaire. A total of $30(56 \%)$ of the respondents belonged to the age group (35 years - 44 years). Out of the 53 respondents, 45 (85\%) were males. Nineteen subjects (36\%) were adult emergency Consultants, 10 (19\%) were pediatric emergency consultants, and 24 (45\%) were staff physicians. The years of practice experience ranged from six months to 25 years, with a median of seven years (IQR 6).

Table 3. MBI-HSS subscale score and interpretation

\begin{tabular}{lllll}
\hline Sub-scale & Mean (SD) & $\begin{array}{l}\text { High risk of } \\
\text { burnout } \mathbf{n}(\%)\end{array}$ & $\begin{array}{l}\text { Average risk of } \\
\text { burnout } \mathbf{n}(\%)\end{array}$ & $\begin{array}{l}\text { Low risk of burnout } \\
\mathbf{n}(\%)\end{array}$ \\
\hline Emotional Exhaustion & $2.72(1.29)$ & $21(40)$ & $14(26)$ & $18(34)$ \\
Depersonalization & $1.86(1.32)$ & $21(40)$ & $17(32)$ & $15(28)$ \\
Personal Accomplishment & $4.52(0.9)$ & $17(32)$ & $18(34)$ & $18(34)$ \\
\hline
\end{tabular}


The comparative values of emotional exhaustion (EE), depersonalization (D) and personal accomplishment (PA) are 2.72, 1.86 and 4.2, respectively. The data are summarized in Table 3.

The scores of different subscales did not differ significantly $(p>.05)$ between different physician groups in our study.

In response to the question about the factors that are likely to negatively affect their relationship to work, work overload was the most important factor among all different groups, followed by insufficient reward (see Figure 1).

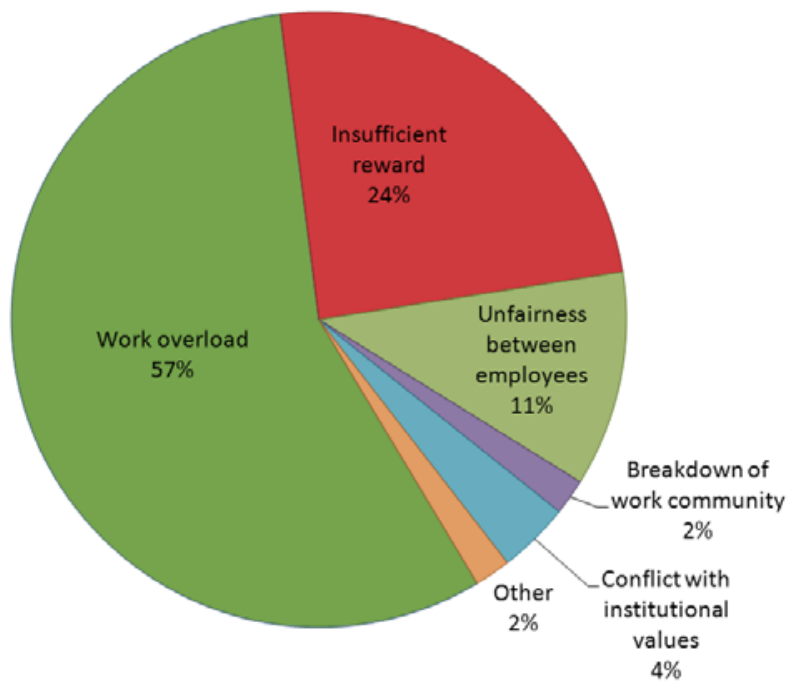

Figure 1. Factors that most negatively affect relationship to work place

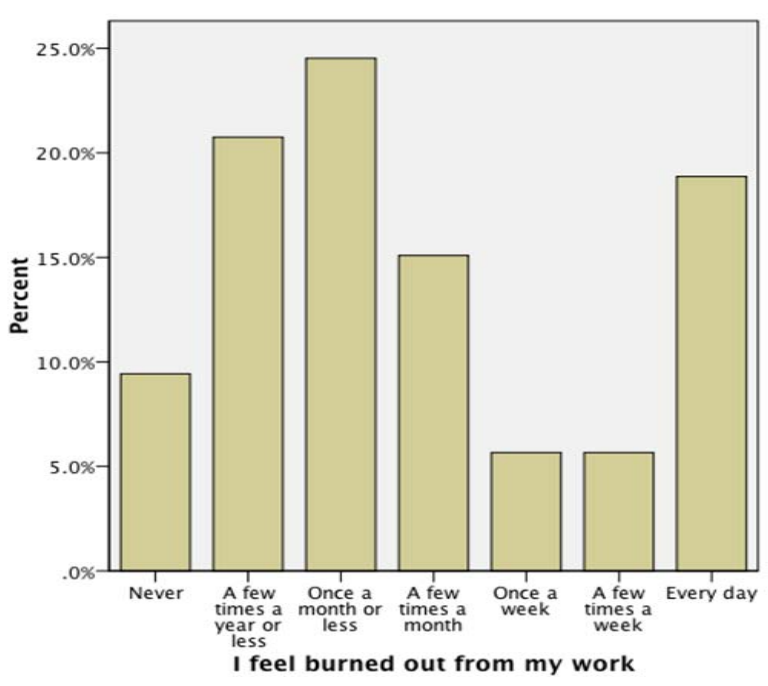

Figure 2. Answers to the question "How often do you feel burned out from your work?”

In regards to coping techniques to alleviate work-related stresses, taking a brake from work; socializing and praying were among the most common answers.

About a third of our participants have the feeling that they are burned out from their work at least once a week (see Figure 2).

\section{Discussions}

This study demonstrates the high burnout risk in Emergency specialists. A number of nation-wide studies from different parts of the world have shown the significant risk of burnout among emergency physicians in particular ${ }^{[5,12-14]}$. In a nation-wide study of 7,288 United States physicians, Emergency Physicians were at a significantly higher risk compared to others ${ }^{[5]}$. This confirms previous findings on higher emotional exhaustion scores among United States emergency physicians ${ }^{[15]}$. Another similar example has been found in a nation-wide study in Romania, where emergency physicians were found to have high emotional exhaustion score as well ${ }^{[13]}$. The mean emotional exhaustion score among our respondents (2.72) was higher than both the US and Romanian studies (2.69, and 2.21 respectively). This finding is particularly important as emotional exhaustion is considered the core manifestation of burnout. Depersonalization scores among our respondents (1.86) were also high in comparison to the Romanian study, although less than the US scores (1.4, and 2.6 respectively). Our personal accomplishment scores were divided roughly in equal thirds between high, average, and low risk groups. However our staff physicians group tended to have lower personal accomplishment scores compared to the consultants group. This group deserves the greatest attention since they were significantly at higher risk of changing specialty or employer. 


\section{Limitations and future directives}

Small sample size and being done at a single site are the main limitations of this study. However we wanted to cover that department initially alone, since it is the main emergency medicine training site, and among the largest departments in the country with the highest number of Emergency Medicine specialists. We plan to do a nation-wide study addressing the same question at a larger scale.

\section{Conclusion}

Our results on moderate to high burnout risk among emergency physicians are consistent with previous reports in the literature. Decision makers should take serious steps to address the threat, in order to minimize the risk of burnout and its impact on physicians as well as the patients they care for.

\section{Acknowledgements}

The authors are thankful to Dr. Abdulaziz Alkhaili for his succor in the present study.

\section{References}

[1] Estryn-Behar, MDM., Gutarni, K., Fry, C., Machet, G., Pelloux, P., Aune, I., et al. Emergency physicians accumulate more stress factors than other physicians-results from the French SESMAT study. Emerg Med J. 2011; 28(95): 397-410. PMid: 21123828. http://dx.doi.org/10.1136/emj.2009.082594

[2] Dunn, PM., Arnetz, BB., Christensen, JF., Homer, L. Meeting the imperative to improve physician well-being: assessment of an innovative program. J Gen Intern Med. 2007; 22(11): 1544-52. PMid: 17891503. http://dx.doi.org/10.1007/s11606-007-0363-5

[3] Spickard, A., Jr, Gabbe, SG., G.S., Christensen, JF. Mid-career burnout in generalist and specialist physicians. JAMA, 2002; 288(12): 1447-50. PMid: 12243624. http://dx.doi.org/10.1001/jama.288.12.1447

[4] Maslach, C., Jackson, SE., Leiter, MP. Maslach burnout inventory manual. Mind garden.com, 3rd Edition, Palo Alto, CA., Consulting Psychologists Press, Inc.; 1996.

[5] Shanafelt, TD., Boone, S., Tan, L., Dyrbye, LN., Sotile, W., Satele, D., et al. Burnout and satisfaction with work-life balance among US physicians relative to the general US population. Arch int med. 2012; 172(18): 1377-85. PMid: 22911330. http://dx.doi.org/10.1001/archinternmed.2012.3199

[6] Tintinalli, JKG., Stapczynski, JS. Emergency Medicine, a comprehensive study guide. 6th edn. New York: McGraw-Hill Companies, Inc.; 2004: 1085-88.

[7] Deckard, G., Meterko, M., Field, D. Physician burnout: an examination of personal, professional, and organizational relationships. Med Care. 1994; 32(7): 745-54. PMid: 8028408. http://dx.doi.org/10.1097/00005650-199407000-00007

[8] Bailey, C., Murphy, R., Porock, D. Professional tears: developing emotional intelligence around death and dying in emergency work. J Clin Nurs. 2011; 20(23-24): 3364-72. PMid: 22017523. http://dx.doi.org/10.1111/j.1365-2702.2011.03860.x

[9] Ahola, K. Occupational burnout and health. Finnish Institute of Occupational Health; 2007. Available from: http://urn.fi/URN:ISBN:978-951-802-795-2.

[10] Beckstead, JW. Confirmatory factor analysis of the Maslach Burnout Inventory among Florida nurses. Int J Nurs Stud. 2002; 39(8): 785-92. http://dx.doi.org/10.1016/S0020-7489(02)00012-3

[11] Naudé, JLP., Rothmann S. The Validation of The Maslach Burnout Inventory - Human Services Survey For Emergency Medical Technicians In Gauteng. SAJ Indus Psychol. 2004; 30 (3): 21-28.

[12] Reinhart, MA., Munger, BS., Rund, DA. American Board of Emergency Medicine Longitudinal Study of Emergency Physicians. Ann Emerg Med. 1999; 33(1): 22-32. http://dx.doi.org/10.1016/S0196-0644(99)70413-0

[13] Popa F., Raed, A., Purcarea, VL., Lala A., Bobirnac, G. Occupational Burnout levels in Emergency Medicine - a nationwide study and analysis. J Med Life. 2010; 3 (3): 207-15. PMid: 20945809.

[14] Popa F., Arafat, R., Purcarea, VL., Lala, A., Popa-Velea, O., Bobirnac, G. Occupational Burnout levels in Emergency Medicine a stage 2 nationwide study and analysis. J Med Life. 2010; 3 (4): 449-53. PMid: 21254747.

[15] Kuhn, G., Goldberg, R., Compton, S. Tolerance for uncertainty, burnout, and satisfaction with the career of emergency medicine. Ann Emerg Med. 2009; 54 (1): 106-13. e6. 